should be clearly given; this requires a full visualization of the finished film while writing the seript. When the script is complete, it is highly desirable to send copies to colleagues in the same field for their comments. This usually improves a film very much; it should be noted, however, that two or three outside critics are sufficient and a committee should be avoided.

After a full discussion of the technical details of the filming and of the apparatus used, Prof. Bogue stressed the need for keeping the original film intact and employing a duplicate for cutting and editing, particularly when "Kodachrome" is used. The script should be broken down into shots, each on an index card with full technical information; the editing can then be carried out largely from this file. This is, of course, the stage at which the film is made or spoilt. The best films demand good presentation if they are to be used successfully. A good-quality projector and screen, suitable for the size of hall and audience, are essential.

After the screening of "Nitrous Oxide-OxygenEther Anæsthesia", there was a discussion which ranged over detailed problems of technique in film making, as well as wider issues regarding the production and use of scientific films. Among the matters discussed were the illumination most suitable for the photographing in colour of fatty tissues, and the desirability of making films on specialized subjects about which there might be controversy.

\section{TECHNICAL EDUCATION IN THE U.S.S.R.}

TN a paper read at the fiftieth annual meeting of 1 the Society for the Promotion of Engineering Education (United States), which has recently been published, J. G. Tolpin, of Universal Oil Products Co., described the progress of technical education in the U.S.S.R. up to the end of the third Five-Year Plan in 1942, with special reference to the engineering industries. It is a record of great achievement in the face of many difficulties, and may be viewed as both cause and effect in an unprecedented industrial expansion since 1914; especially since 1931, when Stalin said that Russia was still fifty to a hundred years behind the world's leading nations, and would have to make up this lag in ten years.

In 1914, manufacturing industry was only about one-twelfth its present size, and the whole country was still mainly agricultural. Moreover, the full extent of her vast natural resources was very inadequately realized compared with the knowledge now acquired by research and exploration. For example, it has now been discovered that the reserves of potassium minerals in Kazakhstan are the largest in the world; and the coal seams of the Pechora region are now estimated at 120,000 million tons. These and many other new discoveries of mineral wealth have meant corresponding developments in industrial activity and consequently an ever. increasing and more urgent need for trained and well-educated workers. The following figures indicate some of the progress made since 1913 :

\begin{tabular}{|c|c|c|c|c|c|}
\hline & & & 1913 & 1937 & 1942 \\
\hline output (mill. tons) & & $\cdots$ & $29 \cdot 1$ & 128 & 230 \\
\hline Iron ore & .. & $\cdots$ & $9 \cdot 2$ & $27 \cdot 8$ & $\rightarrow$ \\
\hline $\begin{array}{l}\text { Oil (mineral) } \\
\text { Sulphuric acid (1,000̉ tons) }\end{array}$ & .. & .. & $9 \cdot 1$ & $28 \cdot 4$ & $48 \cdot 5$ \\
\hline $\begin{array}{l}\text { llphuric acid (1,000 tons) } \\
\text { ectrical energy (bill. kWh.) }\end{array}$ & & . & 121 & 1,666 & 75 \\
\hline Locomotives & $\cdots$ & $\cdots$ & 664 & 1,214 & 2,090 \\
\hline
\end{tabular}

In this period the agricultural population, which represented 80 per cent of the whole in 1913, fell to 55.5 per cent of the total in 1939 ; or, in other words, the non-agricultural wage earners numbered 28 millions in 1938 as compared with 11.2 millions in 1913 ; total population increased to 170.5 millions in 1939. Industrial output has been stimulated not only through the ordinary channels of better trained workers, but also by special methods and incentives, including the distribution of medals and other decorations for specially good work, mention in the general and technical press, and by other means : at the same time poor results due to bad management or otherwise are equally publicized. The total number of youths of 14-17 at present being mobilized for industrial training is nearly $1,000,000$. After preliminary training they will work for four years on State enterprises. In the case of these and possibly other groups, it is said that special inducements are being offered to encourage them to attend the factory technical schools rather than the college grade schools, as the latter do not, it is alleged, turn out quite the right type of skilled workers for industrial plants. In the U.S.S.R., therefore, the old problem met with in other countries of striking a judicious balance between academical and practical or shop training also presents difficulties.

Looking at this matter of technical education and training in more detail, it may be said that the general school organization in the U.S.S.R., like other things in the social system, undergoes constant change, so that, as Tolpin points out, the latest official publication (1940) on school regulations is nearly all new. An important factor in this gradual evolution of the educational policy was the national convention of professors and administrative officers in May 1938, in the Moscow Kremlin, which was attended by Stalin himself. V. M. Molotov then stated that the number of students in college grade schools exceeded the combined figures for Germany, England, France, and Italy, but neither the quantitative nor qualitative objectives had been reached. The total enrolment in all types of schools in 1939 was 34 millions, of whom 600,000 studied in college grade schools. It would scarcely seem that this latter figure is an excessive proportion of the whole, or needed special efforts for its further reduction. There are no sex distinctions, and the Revolution opened all schools equally to men and women, of which the latter seem to have taken full advantage. They are now active in every field of technical and professional work and in all branches of social research. In 1939 sixty per cent of all physicians were women, and in the Bashkir country the percentage reached 75. Many of them are directors of research in medicine and other sciences, pure and applied. Women formed more than 41 per cent of the total of college students in 1939, and 27 per cent in the technical (factory) schools. The most marked advance in this respect has been in the Moslem countries (for example, Uzbekistan and Turkmenia), as might be expected, since in such countries women had much further to travel along the paths to emancipation than in others.

Nor is any distinction made in regard to national minorities or in the numerous parts of the Soviet Union where the native language is not Russian, such as the Ukraine, Georgia, Armenia, White Russia, and parts of Siberia. There are more than a hundred different languages and dialects altogether in the Union, of which more than sixty are recognized for use in public institutions. Many newspapers and 
technical journals are printed in these languages, and Russian itself is merely one of the more important subjects of instruction in the schools.

In the early years after the Revolution, schools for adults formed an important part of the Russian educational system, and were strongly supported by the State. Adult students numbered 320,000 in 1932 ; but the numbers are, of course, gradually declining, as the younger generation, much better educated than its forbears, is growing up. Among all classes of the population-old and young-there is a zeal and keenness for education, stimulated by the teachings of Lenin and other early leaders; but for some time there was a serious lack of suitable teachers. In 1939 the number of professorships or chairs was about 10,000, more than half of which were held in the technical and agricultural colleges; while the total teaching staff was a little more than 40,000. Education is mostly entirely free, and some 90 per cent of the students of college grade schools receive grants.

Special attention is, of course, devoted to vocational training, and the aim is to give at least a minimum of technical training to every worker, including labourers. The Five-Year Plan ending 1942 called for the training of more than 9 million persons for work in industry in different capacities. The technical schools in the Soviet Union, in addition to the higher college grade schools or universities, include also the 'technicums' or secondary technical schools. In 1938 there were in existence 3,400 of these, and it was expected that the number of students would reach 800,000 in 1942. For admission to a 'technicum', seven years of preliminary schooling is required, as compared with ten years for the college grade school ; and the course lasts four years.

The factory schools fulfil important functions in training qualified workers. They were reconstituted in a different form in 1940. During the first FiveYear Plan these schools trained 450,000 workers; treble that number during the second; and the number planned for the third was $1,700,000$. In addition to purely vocational training, they give a certain amount of general and political education, and also special training designed to meet the needs of any particular industry.

Special facilities, largely controlled by the Committee for Higher Education in Moscow, are provided for a first-class engineering training for students who have taken the general courses in secondary schools and have reached the age of 19-20. These are available either in the universities or technical colleges, and extend over five years, with examinations every year. The programme of study comprises almost the same basic subjects as those of engineering schools in other countries, with a few exceptions. In the case of non-Russian students, ample provision is made for the study of Russian for the first two years, the time being taken out of that allotted for foreign languages. Social and economic science and philosophy are included, with particular reference to that of the Communist Party. Parentheticelly, it may be remarked that this philosophy is not necessarily the same as it was in the early days : one of the points most strongly emphasized by Lenin was that social philosophy must be constantly subject to change and evolution, and this appears to have been confirmed in the recent history of the Soviet Union. In regard to foreign languages, it is interesting to note that, until lately at all events, English was the foreign language to be studied by petroleum engineers, whereas German was preferred for mechanical engineers.

Special efforts are made to provide sufficient numbers of the right kind of fully trained teachers for the engineering courses ; and no money is spared in buildings and equipment, in facilities for research, and so forth. More attention also is now being given to the matter of patents for invention, with the view of making the patent system a more effective means of encouragement in developing the inventive skill or genius of students. Employment bureaux are an essential part of the organization, but their chief difficulty is that there are always more positions open than applicants to fill them. The 150,000 young engineers and scientific agriculturists trained in more than two hundred technical colleges during the third planned period were certain to be less than the number required. Provision is also made for postgraduate work and preparation for D.Sc., D.Ph. and other degrees. In view of the shortage of trained men just mentioned and the vast programme of rebuilding, etc., at the end of the War, it is thought there may be scope and opportunity for collaboration with British and American engineers, and no doubt this is already under careful consideration in the right quarters.

\section{NATIONAL RESEARCH COUNCIL, CANADA}

THE twenty-sixth annual report of the National Research Council, Canada, 1942-43, includes the report of the president together with the reports of the directors of the Divisions of Applied Biology, Chemistry, Mechanical Engineering, Physics and Electrical Engineering, of the Section on Codes and Specifications and of the Research Plans and Publications Section. Owing to war-time requirements, publication of the "Review of Activities" has been discontinued temporarily. The National Research Council is now serving as a central co-ordinating body directing scientific research in Canada, within its own laboratories, in the universities and in industry, and the Council has been appointed the official research station of the Navy, Army and Air Force in Canada.

With the exception of a long-term project on forest-tree breeding, the work in the Division of Applied Biology is now wholly related to the war effort. The pre-war staff of nine has been increased to twenty-nine to cope with the food problems submitted by various Government departments. Investigations on modified curing practices have led to the adoption of a standard cure, with the result that Canadian bacon is now held in higher favour on the British market than ever before, and even under war-time conditions of transport and storage the proportion of Canadian bacon de-graded by the British Ministry of Food is so exceptionally small that rigorous inspection is no longer considered necessary. Studies on egg-shell treatment to extend the storage life of eggs under the storage and transport conditions of war-time have been completed and large-scale investigations undertaken to determine the best conditions applicable in industry for processing and storing dried eggs. Standard canning procedures in line with the Council's findings have been adopted by manufacturers of canned pork and ham, and a laboratory method has been developed 